\title{
VIESTINNÄN ETNOGRAFIA JA SUOMALAINEN PUHEKULTTUURI
}

\section{Saila Poutiainen}

\section{TIIVISTELMÄ}

Suomalaista puhekulttuuria on viimeisen kymmenen vuoden aikana tutkittu paljon viestinnän etnografisesta (ethnography of communication) näkökulmasta. Viestinnän etnografia on sosiaalis-konstruktionistinen lähestymistapa tai teoria viestinnän tutkimukseen, jossa ensisijaisena tavoitteena on kuvata ja tulkita puheyhteisöä ja viestinnän kulttuurisia piirteitä puheyhteisön jäsenten näkökulmasta. Artikkelissa esitellään viestinnän etnografian historiaa 1960-luvulta lähtien, avataan viestinnän etnografisen tutkimuksen sisältämiä käsityksiä viestinnästä ja kulttuurista, esitellään erityisesti suomalaisesta puhekulttuurista tehtyä viestinnän etnografista tutkimusta sekä kuvataan viestinnän etnografiaan kohdistettua kritiikkiä.

Asiasanat: viestinnän etnografia, viestintäkulttuuri, suomalainen puhekulttuuri, viestinnän tutkimus

\section{JOHDANTO}

Viestinnän etnografia on yksi tulkitsevista tai sosiaalisista näkökulmista viestinnän tutkimukseen. Viestinnän etnografisissa tutkimuksissa, kuten vaikkapa keskustelunanalyysissä, kulttuurintutkimuksessa, feministisessä viestinnän tutkimuksessa, etnometodologiassa tai erilaisissa diskurssianalyyseissä on tavoitteena ymmärtää ja tulkita sitä, miten ihmisten arkipäiväisissä viestintätilanteissa uudelleen tuotetaan merkityksiä ja sosiaalista todellisuutta. Tulkitsevan tai sosiaalisen näkökulman vastakohtana nähdään viestinnän objektivistinen siirtomalli (ks. esim. Carey 1989; Craig 1999, 124 
128; Leeds-Hurwitz 1995, 3), jossa merkityksiä voidaan tarkastella yksilöltä toiselle siirrettävinä ja viestintää tai esimerkiksi sen määrää yhtenä muuttujana. Viestinnän etnografiassa, kuten muissa tulkitsevissa näkökulmissa, tutkijat ovat kiinnostuneita kuvaamaan viestintää holistisesti, reflektoiden, viestijöiden näkökulmasta ja usein kvalitatiivisin menetelmin. (Leeds-Hurwitz 1995, 6-11.)

Puheen etnografisena tutkimuksena alkanut viestinnän etnografinen tutkimus liitetään usein kielitieteeseen ja erityisesti sosiolingvistiseen tutkimukseen. Antropologian tutkimuksella on yhteistä myös viestinnän etnografisten tutkimusten kanssa, ja niin kutsuttujen tulkitsevien antropologien, kuten Clifford Geertzin (1973) ja David Schneiderin (1976), näkemykset kulttuurista ja sen tutkimuksesta ovat yhteneviä viestinnän etnografien tekemien tulkintojen kanssa. Huolimatta näistä "sukulaisuuksista" viestinnän etnografia on nimenomaan viestinnän tutkimusta. Viestinnän etnografinen tutkimus sijoitetaan viestinnän tutkimuksessa usein kielen ja sosiaalisen vuorovaikutuksen tutkimuksen kentälle. Esimerkiksi suurimmissa kansainvälisissä konferensseissa viestinnän etnografisia tutkimuksia esitellään erityisesti Language and Social Interaction (LSI) -ryhmissä, mutta myös muissa.

Viestinnän etnografisissa tutkimuksissa kuvataan puheyhteisöjä, niiden ainutlaatuisia viestinnän kulttuurisia piirteitä tai ilmiöitä sekä yleisemmin viestinnän kulttuurisuutta. Viestinnän etnografisissa tutkimuksissa pyritään ymmärtämään viestintää ja maailmaa viestijöiden itsensä, niin sanottujen natiivien eli paikallisten, näkökulmasta. Lisäksi viestinnän etnografiassa pyritään esittämään vertauksia ja rinnastuksia puhekulttuureiden ja niiden piirteiden välillä ja tarkastelemaan viestinnän mahdollista universaaliutta.

Aloitan esitykseni tarkastelemalla viestinnän etnografian historiaa, jonka jälkeen avaan viestinnän etnografisen tutkimuksen sisältämiä käsityksiä viestinnästä ja kulttuurista ja esittelen viestinnän etnografista tutkimusta sekä viestinnän etnografiaan kohdistettua 
kritiikkiä. Lopuksi kuvaan viestinnän etnografisen tutkimuksen tuloksia suomalaisesta puhekulttuurista.

\section{VIESTINNÄN ETNOGRAFIAN SYNTY}

Kielitieteilijän ja antropologin koulutuksen saanut Dell Hymes esitti vuonna 1962, että puheen tutkimus sellaisenaan, "omien malliensa ehdoilla" (Hymes 1962, 10), ei ollut saanut riittävää huomiota. Hymesin mukaan antropologisissa tutkimuksissa kieli ja erityisesti kielenkäyttö oli liian usein sivuutettu ja puolestaan kielitieteellisissä tutkimuksissa ei ollut oltu riittävän kiinnostuneita kielenkäytön sosiaalisesta tai kulttuurisesta ympäristöstä. Hymesin mukaan ihmisen sosiaalisen toiminnan tutkimuksessa oli unohdettu tai ainakin laiminlyöty sosiaalisten merkitysten, niiden erojen ja kielen sosiaalisen käytön tarkastelu, eikä kielitieteessä tai antropologiassa ollut omaa sijaansa puheelle ja viestinnälle. Hymes, joka oli muun muassa Erving Goffmanin, Emanuel Schefloffin sekä Ray Birdwhistellin aikalainen ja kollega (Leeds-Hurwitz 2005, 342), esitti vuonna 1962 ajatuksen puheen etnografiasta (ethnography of speaking). Hymes kehitti näkemyksiään kymmenen vuoden aikana ja teki vuonna 1972 ohjelmallisen julistuksen viestinnän etnografian (ethnography of communication) tutkimukselle.

Viestinnän tutkijat käyttävät edelleenkin, Hymesin tapaan, puheen etnografian ja viestinnän etnografian termejä sekä puheyhteisön ja viestintäyhteisön käsitteitä toistensa synonyymeina (englanniksi viestinnän etnografia ja viestintäyhteisö lienevät yleisemmin käytössä). Hymes (1972) toteaa, että esittämässään puheen, kielenkäytön ja viestinnän kuvaukseen pyrkivässä lähestymistavassa ja tutkimuksessa ei ole kyse vain puheen tutkimuksesta vaan että hän tarkoitti puhe-sanalla laajemmin kaikkea viestintää. Viestinnän etnografia on alusta asti ollut niin puhutun ja kirjoitetun kuin eiverbaalisenkin viestinnän tutkimusta.

Hymesin vuonna 1972 julkaistussa, ehkä historiallisesti viestinnän etnografisen tutkimuksen keskeisimmässä artikkelissa, on kolme 
periaatetta, jotka mielestäni ovat ohjanneet viestinnän etnografisia tutkimuksia tähän päivään saakka. Ensinnäkin Hymes osoittaa useiden kirjallisuus- ja aineistoesimerkkien avulla, että viestinnän etnografiselle tutkimukselle on paikkansa. Kielitieteellisen ja antropologisen tutkimuksen kohteisiin verrattuna viestinnän etnografiassa tutkimuksen kohteena on nimenomaan viestintä - eivät kielen rakenteet eivätkä kulttuurin tavat toimia. Viestinnän etnografisille tutkimuksille on tänäkin päivänä yhteistä se, että tutkimuksen kohteena on sekä kulttuurinen viestintä että viestinnän näkökulmasta tarkasteltuna kulttuurin kuvaus. Toiseksi Hymes korostaa puheen tai kielenkäytön kulttuurista variaatiota. Hymes esittää toistuvasti, että variaation tutkimusta tarvitaan lisää ja että variaation ymmärtäminen ja kuvaaminen on arvokasta. Kolmanneksi Hymes korostaa kuvailevan teorian ja tutkimuksen arvoa ja esittää konkreettisia välineitä, kuten käsitejärjestelmää, puheyhteisöjen kuvaamiseen ja vertaamiseen. (Hymes 1972, 38-71.)

Viestinnän etnografisissa tutkimuksissa pyritään puhe- tai viestintäyhteisöjen systemaattiseen kuvaukseen Hymesin luomien käsitteiden avulla. Hymesin käsitejärjestelmä sisältää analysoitavien sosiaalisten yksiköiden määritelmiä sekä erilaisten viestintätilanteiden kuvaamiseen luodun SPEAKING-muistisäännön. Hymes (1972) esittää, että keskeiset sosiaaliset yksiköt puhekulttuurien kuvaamisessa ovat puheyhteisö, puhetilanne, puhetapahtuma ja puheteko. Puheyhteisö (speech community) on käsitteistä keskeisin, ja sillä tarkoitetaan sellaista yksikköä, ihmisryhmää, jolla on yhteiset säännöt viestinnän tuottamiseen ja tulkitsemiseen sekä ainakin yhden kielellisen variaation tulkitsemiseen. Hymesin (1972) esityksen mukaan puheyhteisöissä tapahtuvat seremoniat, juhlat, ateriat ja rituaalit (kuten teekkarityttöjen säännölliset saunaillat) ovat puhetilanteita (speech situation). Puhetapahtumia (speech events) ovat puolestaan puhetilanteiden viestintätoiminnot (esimerkiksi saunailloissa käydyt keskustelut teekkaripojista). Puheteko on Hymesin käsitejärjestelmässä esimerkiksi keskustelun aikana kerrottu vitsi (kuten teekkarityttöjen kertoma teekkaripoikavitsi). (Hymes 1972, 52-59.) 
Hymes (1972, 36-37) esittää, että vaikka kielen(käytön) tai puheen huolellista analysointia ei tulisi tutkimuksessa unohtaa, viestinnän etnografisessa tutkimuksessa perusanalyysiyksikkö on yhteisö tai ryhmä ja sen viestintä. Milburn (2004) analysoi 70:tä viestinnän etnografista tutkimusta ja toteaa, että tutkimusraporteissa ei määritellä puheyhteisöä yksimielisesti eikä Hymesin alkuperäisten kuvausten mukaan. Puheyhteisön käsitettä ja sen käyttöä tulisi siis tarkistaa, jotta perusanalyysiyksikkö säilyisi merkityksellisenä viestinnän etnografisissa tutkimuksissa.

Hymes (1972) esitti osana käsitejärjestelemäänsä SPEAKINGmuistisäännön muotoon laaditun puhetilanteiden kuvaussanaston, jossa muistisäännön kirjaimet muodostuvat puhetilanteen osatekijöistä: S (situation, scene, setting) tarkoittaa puhetilanteen fyysistä ja ajallista asetelmaa, P (participants) puhetilanteeseen osallistuvia ja siinä toimivia ihmisiä ja heidän sosiaalisia ja vuorovaikutusroolejaan, E (ends) sekä puhetilanteen tavoitteita että lopputulemaa, A (acts) puhetekoja, niiden jaksoja, puheenvuoroja ja myös itse puheen aiheita, $\mathrm{K}(k e y)$ puhetilanteen sävyä, tyyliä tai ilmapiiriä, I (instrument) puhetilanteessa käytettyjä viestinnän kanavia tai välineitä, N (norms) puhetilanteen normeja, sääntöjä tai säännönmukaisuuksia ja G (genre) puhetilanteen genreä. (Hymes 1972, 59-66.)

Suomalaisessa tieteellisessä kirjallisuudessa on kuvattu tähän mennessä erittäin vähän viestinnän etnografista tutkimusta. Yksi harvoista aiheesta kirjoittaneista on Hakulinen (1989), joka tarkastelee kriittisesti juuri edellä esitettyä muistisääntöä. Hakulisen mukaan puhetilanteen kuvaaminen muistisäännön avulla voi olla vaikeaa, sillä vain osa piirteistä on paljain silmin havaittavissa ja osan eksplikoiminen, kuten puhetilanteessa ilmenevien sääntöjen tunnistaminen, on jo tutkimustehtävä sinänsä. Hakulinen myös kysyy, onko piirteillä tärkeyshierarkia, ovatko kaikki piirteet aina näkyvissä, miten piirteet ovat kietoutuneet toisiinsa ja miksi ylipäätään määritellä, mikä on puhetilanne. Miksi puhetoimintaa ei 
voitaisi luonnehtia sellaisenaan mainituista piirteistä riippumatta? (Hakulinen 1989)

Mielestäni Hakulisen yksityiskohtaiset kysymykset ovat aiheellisia. Ymmärrän silti myös piirteiden kuvauksen tarkoituksen. Viestinnän etnografiassa ensisijainen tavoite on kuvata viestintää, ja Hymesin käsitteistö pyrkii tähän tavoitteeseen kahdella tavalla. Toisaalta tutkijalla on käsitteistön avulla mahdollisuus tavoitella viestintätekojen holistista kuvausta (Carbaugh, Gibson \& Milburn 1997, 5). Huolimatta siitä, että joidenkin piirteiden määrittely voi olla liian epämääräistä, Hymesin esittämä käsitteistö on varsin kattava muun muassa puhetilanteiden kuvaamiseen. Toisaalta Hymesin käsitteistöä käyttämällä vertaileva analyysi mahdollistuu - käsitteistöä voidaan käyttää osatekijöiden systemaattisten suhteiden paikantamisessa, ja käsitteistö tarjoaa yhteisen kielen viestinnän etnografeille. Vertailevat kuvaukset mahdollistavat myös tämän kuvailevan viestinnän teorian kehittämisen (Carbaugh 1995b, 279). Philipsenin $(1990,261)$ mukaan Hymesin käsitteistö ei vain ohjaa tutkijoita ja heidän tutkimuksiaan, vaan myös tutkimukset muokkaavat ja kehittävät Hymesin aloittamaa työtä. Näin kuvaamiseen ensisijaisesti tähtäävä lähestymistapa pysyy empiriasta nousevana ja teoreettisesti kehittyvänä näkökulmana (Philipsen 1990, 261).

Esimerkkinä SPEAKING-muistisäännön soveltamisesta on Katrielin ja Philipsenin (1990) tutkimus communication-rituaalista. Communicationilla ei tässä viitata tieteenalaan tai tutkijoiden käyttämään abstraktiin käsitteeseen vaan sellaiseen amerikkalaiseen arkipuheeseen, joka on osallistujille tärkeää ja osallistujien välistä suhdetta ylläpitävää. Katriel ja Philipsen kuvaavat communication-rituaalia SPEAKING-muistisäännön avulla sellaiseksi, joka tapahtuu yksityisessä paikassa (S), jossa puhuminen on keskeinen toiminta ja jossa osallistujat voivat täysin syventyä puhumiseen. Osallistujat (P) ovat toisilleen läheisiä (esimerkiksi perheenjäseniä), ja he kokevat jonkin "ongelman" yhteiseksi ja ongelmasta puhumisen aiheelliseksi. Rituaalin tavoitteena (E) on ongelman 
ratkaiseminen siitä keskustelemalla sekä keskusteluun osallistuvien identiteetin vahvistaminen ja läheisyyden aikaan saaminen ja kokeminen. Rituaalissa sisältönä (A) on yksilön kokemus itsestä ja maailmasta ja niiden välisestä suhteesta. Tämä kokemus on pikemminkin interpersonaalisesti kuin intrapersonaalisesti koettu, alituiseen ongelmia aiheuttava ja siksi puhumista vaativa. Rituaali alkaa toisen osapuolen ehdotuksella, että osapuolet "sit down and talk about it [ongelmasta]" (Katriel \& Philipsen 1990, 86). Toinen osapuoli tunnustaa, että ongelma on olemassa ja ehdotus aiheellinen. Osapuolet puhuvat ja keskustelussa muotoillaan ongelma ja sen osatekijät. Osatekijöitä ja niiden seurauksia tarkastellaan mahdollisimman monista näkökulmista. Keskustelun ehdottaja kertoo paljon itsestään, toinen osapuoli kuuntelee arvostelematta. Communication-rituaali päättyy ristiriitaisten näkemysten ratkaisemiseen tavoitteena suhteen kariutumisen uhan lieventäminen. (Katriel \& Philipsen 1990, 86-88.)

\section{VIESTINNÄN ETNOGRAFIAA - VIESTINNÄN TUTKIMUSTA}

Gerry Philipsenin klassikkoartikkeli Speaking like a man in Teamsterville (1975) on ensimmäinen Hymesin kehittämän puheen etnografian sovellus nimenomaan viestinnän tieteenalalla. Tutkimuksessa kuvataan sukupuolittuneita viestinnän paikkoja, muotoja ja tapoja 1960-70-lukujen taitteessa Chicagon lähellä Teamsterville-nimisessä työväenluokkaisessa yhteisössä. Philipsen vietti yhteisössä kaikkiaan yli kaksi vuotta työskennellen muun muassa sosiaalityöntekijän tehtävissä. Philipsen esittää artikkelissaan, että Teamstervillessä miesten viestintätilanteet voidaan jakaa kolmeen ryhmään: tilanteisiin, joissa 1) miehet puhuvat verrattain paljon, 2) miehet puhuvat verrattain vähän ja joissa 3) puhumisella ei ole sijaa miesten toiminnassa ja miesten on ilmaistava itseään muilla keinoilla. Paljon puhuminen nähtiin yhteisössä miehille sopivaksi, kun vuorovaikutukseen osallistujien suhde oli symmetrinen, ja puolestaan epäsopivaksi, kun suhde oli epäsymmetrinen. Epäsymmetrisiksi suhteiksi kuvattiin esimerkiksi miehen suhdetta 
vaimoonsa, lapsiinsa tai naapuruston ulkopuolisiin jäseniin. Miehet tietysti puhuivat vaimojensa kanssa, mutta yhteisössä oletettiin, etteivät mies ja vaimo puhu paljon keskenään. Puhumisella ei nähty lainkaan sijaa miesten toiminnassa silloin, kun heidän odotettiin reagoivan sukulaisnaisiin tai tyttöystäviin kohdistuneisiin loukkauksiin, kun he pyrkivät vaikuttamaan statushierarkiassa alemmalla tasolla olevan (esimerkiksi lapsen) käyttäytymiseen tai kun heidän oli osallistuttava yhteiskunnalliseen elämään. Näissä tilanteissa miehen oletettiin toimivan esimerkiksi väkivaltaisesti, nonverbaalisesti uhaten tai suhteitaan käyttämällä. Teamstervillessä asuva mies näyttäytyi ulkopuolisille sisäänpäin kääntyneenä, hiljaisena, kielellisesti jälkeenjääneenä ja jurona, kun taas yhteisön omasta näkökulmasta katsoen puhuminen nähtiin miehen rooliin sopivaksi viestintäkeinoksi vain vertaisten kanssa viestiessä. (Philipsen 1975.)

Viestinnän alalla on tehty 45 vuotta Hymesin ensimmäisten kirjoitusten jälkeen ja 30 vuotta ensimmäisen viestinnän etnografisen tutkimuksen julkaisun jälkeen lukuisia kuvauksia puheyhteisöistä ja niiden viestinnästä eri tasoilla, eri puolilla maailmaa. Vuoteen 1986 mennessä viestinnän etnografisia tutkimuksia oli julkaistu jo yli 250 (Philipsen \& Carbaugh 1986). Muutamista viestintäkulttuureista on kertynyt jo varsin mittavasti viestinnän etnografista tutkimusta: israelilaisten (Bloch 2003; Katriel 1986), keskiluokkaisten amerikkalaisten (middle-American) (ks. erityisesti Carbaugh 1988b; Philipsen 1992), läntisten apassien (Basso 1979; 1990b), mustajalkaintiaanien (Carbaugh 2001; Carbaugh \& Rudnick 2006) sekä suomalaisten (esim. Carbaugh 1995a; Carbaugh, Berry \& Nurmikari-Berry 2006; Poutiainen 2007; Wilkins 1999) puhekulttuurista tiedetään tällä hetkellä enemmän kuin muista puheyhteisöistä.

Viestinnän etnografisissa tutkimuksissa on tarkasteltu viestinnän eri merkkijärjestelmiä, ilmiöitä ja tasoja, kuten hiljaisuutta (Basso 1990a; Braithwaite 1990; Carbaugh, Berry \& Nurmikari-Berry 2006), nonverbaalista viestintää (Ray 1987), puhutteluja (Fitch 
1998; Winchatz 2001), interpersonaalista ideologiaa (Fitch 1998), esiintymistä yleisöpuhe- tai julkisissa tilanteissa (Wilkins 2005), esiintymistaidon opetusta (Carbaugh 1998), terveysviestintää (Ho 2006; Suopis \& Carbaugh 2005), retoriikkaa kuntatason päätöksenteossa (Townsend 2004), yksityishenkilöiden poliittista viestintää (Huspek \& Kendall 1991), poliitikkojen viestintää ja viestintää politiikasta (Coutu 2000), viestintää organisaatioissa (Hall \& Valde 1995; Sequiera 1993), viestintää eri medioissa, kuten televisiossa (Carbaugh 1988b), radiossa (Katriel 2004) ja elokuvissa (Philipsen 1992), viestintää teknologiasta (Hiemstra 1983; Poutiainen 2007) sekä viestintää luonnossa ja luonnosta (Carbaugh 1999; Sawyer 2005). Edellä mainituilla viestinnän etnografisilla tutkimuksilla on paljon yhteistä. Tutkimuksissa on sitouduttu paikallisten (natiivien) elämän ja usein arkipäivän viestinnän tarkasteluun. Tutkimuksissa kuvataan nimenomaan yhteisön jäsenten omia tulkintoja ja maailmankuvaa. Tutkimuksissa lähestytään viestintää kulttuurisena, ja niissä kuvataan puheyhteisöjen ja niiden viestinnän uniikkeja kulttuurisia piirteitä. Tutkimuksissa on vertaileva ote - niissä esitetään vertauksia ja rinnastuksia muihin puhekulttuureihin ja pohditaan viestinnän universaaleja piirteitä. Lisäksi useissa tutkimuksissa tutkittavien viestintätekojen ja -tilanteiden kuvaus on sisältänyt kenttätyömenetelmiä.

Kenttätutkimuksella tai osallistuvalla havainnoinnilla viestinnän tutkija tavoittelee tietoa ihmisten tavoista järjestää viestintäänsä ja niistä ilmaisuista, muodoista ja merkityksistä, jotka ovat tutkittavalle yhteisölle erityisen merkityksellisiä. Esimerkiksi Fitchin (1998) kuvaus kolumbialaisista keskiluokkaisista professionalesyhteisön jäsenistä perustuu useamman vuoden aikana tehdylle kenttätutkimukselle ja sen aikana tallennetuille kenttämuistiinpanoille erilaisista julkisista ja yksityisistä vuorovaikutustilanteista (vierailut, juhlat, opetustilanteet, perheen kokoontumiset, työpaikat jne.), lukuisten informanttien haastatteluille ja luonnollisten vuorovaikutustilanteiden äänitallennuksille. 
Vaikkakin osallistuva havainnointi ja siihen liittyvät informanttien haastattelut ovat viestinnän etnografisissa tutkimuksissa tyypillinen aineistonkeruumenetelmä, kenttätyömenetelmien käyttö ei kuitenkaan yksin määritä tutkimusta viestinnän etnografiaksi. Lisäksi kenttätyön merkitys on toisille viestinnän etnografeille tärkeämpi kuin toisille. Esimerkiksi Suter (2000) ei määritellyt tutkimustaan viestinnän etnografiaksi, koska hän ei "onnistunut" keräämään aineistokseen niin sanottuja luonnollisia keskusteluja. Toisaalta viestinnän etnografisten tutkimusten aineistot voivat olla hyvin monipuolisia eikä osallistuva havainnointi ole kaikissa tutkimuksissa tarpeen, mahdollista tai keskeisin aineistonkeruumenetelmä. Esimerkiksi Coutu (2000) on tarkastellut suositun amerikkalaisen Vietnamin sotaa käsittelevän tietokirjan ja kirjaan liittyvän medioidun keskustelun, sekä puhutun että kirjoitetun, sisältämiä vastakkaisia puhekoodeja. Philipsen (1992) ja Berry (1995) ovat analysoineet puhekoodeja ja kulttuurisia käsityksiä Kramer vs. Kramer -elokuvassa. Poutiaisen (2007) tutkimuksessa pääasiallisena aineistona ovat mediatekstit ja haastattelupuhe. Carbaughin (1988b) tutkimuksen aineistona ovat amerikkalaisen Donahue- talk show'n keskustelut. Huolimatta erilaisista strategioista ja keinoista kerätä aineistoa paikallisten (tai natiivien) näkökulmien kuunteleminen on viestinnän etnografisten tutkimusten ytimessä.

Jokaista viestintäsysteemiä tai puheyhteisöä voidaan pitää löytämisen ja kuvaamisen arvoisena, koska ne ovat aina ainutlaatuisia. Philipsen (1990, 258-260) viittaa puhekulttuurien ainutlaatuisuuteen puhuessaan "erityisyyden aksioomasta" (axiom of particularity). Viestinnän etnografit ovat sitoutuneet tarkastelemaan viestintää systeeminä, joka on kulttuurisesti rakentunut, kulttuurisesti toimiva ja uudelleen tuotettu. Viestinnän (systeemin) kulttuuristen piirteiden tutkimus on viime kädessä kuvausta niistä arvoista ja oletuksista, joita puheyhteisössä liitetään ihmisenä olemiseen, sosiaalisiin suhteisiin ja itse viestintään. Carbaugh $(1995 b, 274)$ tiivistää viestinnän kulttuurisuuden seuraavaan ajatuspolkuun: jos viestintää tarkastellaan toimintana, jolla on jotain tekemistä merkitysten kanssa, jos merkitykset liittyvät jotenkin osallistujien näkö- 
kulmiin ja jos osallistujien näkökulmilla on jotain tekemistä heidän kulttuurisen orientaationsa kanssa, viestintä "creatively evokes cultural meaning systems" - viestintä tuo luovasti esiin kulttuurisia merkitysjärjestelmiä (korostus alkuperäisessä lähteessä).

Kun viestintä nähdään lähtökohtaisesti kulttuurisena, on tutkijalla kaksi reittiä, joita pitkin hän voi päätyä kulttuurisen viestinnän kuvaukseen. Tutkija voi toisaalta löytää aineistostaan yhteisön jäsenille merkittäviä ja toistuvia viestinnän ilmiöitä, joiden huolellisesta ja systemaattisesta kuvauksesta tulee viestinnän etnografian tavoite. Tutkija voi myös lähestyä tutkimaansa yhteisöä jonkin olemassa olevan konstruktion avulla (esimerkiksi puhuttelujen, normien, kasvojen säilyttämisen tai hiljaisuuden) ja kuvata (jopa) universaaliksi määritellyn viestinnän konstruktion kulttuurista ilmenemistä valitsemassaan yhteisössä. Jälkimmäisen reitin opastukseksi Philipsen $(2002,61)$ ehdottaa, että erityisen hyvin kulttuurisia piirteitä, arvoja ja asenteita paljastavia viestinnän muotoja ovat viestinnän rituaalit, tarinat, myytit ja narratiivit, sosiaaliset draamat ja paikalliset meta-viestinnän sanastot. Näitä käsitellään seuraavassa hieman yksityiskohtaisemmin.

1) Rituaalin katsotaan muodostuvan säännönmukaisessa järjestyksessä etenevistä toimintajaksoista (act sequences). Rituaalin avulla yksilöt tuottavat tai korostavat koettua yhteisöllisyyttä kunnioittaen yhteisesti tärkeiksi koettuja arvoja (Hall 1997). Rituaalit liittyvät tyypillisesti arkipäivän kokemuksiin. Esimerkiksi Fitch (1997) on kuvannut kolumbialaisessa yhteisössä vierailujen lopussa tapahtuvaa lähtemisen yrittämisen rituaalia, jossa on neljä vaihetta: 1) Vieraat ilmoittavat aikeensa lähteä, ja joku vieraista kiittää isäntäväkeä kutsusta. 2) Isäntäväki kysyy, miksi vieraat ehdottavat poislähtemistä, ja vastustaa lähtemisen ajoitusta. 3) Vieraat toistavat lähtöaikeensa tai esittävät lähtemiselle syyn. 4) Isäntäväki vastustaa syytä tai ehdottaa vaihtoehtoisia syitä vierailun jatkamiseksi. Fitch tallensi ääninauhalle ja kenttämuistiinpanoihinsa yhteensä yksitoista lähtemisen yritystä ja päätyy analyysissään siihen, että rituaalissa puheyhteisön jäsenet yhdessä toimien merkityksellistävät yhteisesti tärkeäksi koetun "vinculon". Vinculo tarkoittaa 
interpersonaalista suhdetta, joka on muodostunut konkreettisesti tai symbolisesti jossakin sosiaalisessa tilanteessa, kuten aterialla, leikkisässä jalkapallopelissä, lauluillassa tai vierailun aikana. Fitchin $(1997,185)$ mukaan ihminen nähdään Kolumbiassa ensisijaisesti suhteidensa risteyksenä ja interpersonaaliset suhteet ovat ihmisenä olemisen perusta. Lähtemisen yrittämisen rituaalissa tuotetaan uudelleen ja korostetaan interpersonaalisten suhteiden erityistä arvoa.

2) Tarinoissa, myyteissä ja narratiiveissa yksilöt ja yhteisöt tuottavat uudelleen, hyväksyvät ja ottavat käyttöönsä identiteettejä. Esimerkiksi Poutiaisen (2007) tutkimuksessa kuvattiin sitä, miten suomalaiset tuottivat uudelleen suomalaisuuspuhetta eli myyttiä suomalaisuudesta keskusteluissa ja kirjoituksissa matkapuhelimesta. Nationalismin aikakaudella syntynyt myytti ilmenee matkapuhelinviestintäkuvauksissa toisaalta suomalaisuuden arvosteluna (suomalaisia tulee kouluttaa, suomalaiset eivät osaa käyttää matkapuhelinta yhtä hyvin kuin muut eurooppalaiset jne.) ja toisaalta suomalaisten ominaispiirteiden kuvauksina (suomalaiset haluavat pitää välimatkaa toisiinsa ja siksi matkapuhelin sopii suomalaisille viestintävälineeksi jne.).

3) Sosiaalisen draaman prosessissa paljastuu viestinnän säännönmukaisuus, jota testataan tai josta neuvotellaan sosiaalisessa draamassa. Turnerin (1980) mallia sosiaalisesta draamasta on alun perin käytetty antropologiassa, mutta sitä on sovellettu myös viestinnän kulttuuristen piirteiden, erityisesti ristiriitojen kuvaamiseen. Sosiaalinen draama alkaa välirikosta tai sosiaalisen järjestyksen rikkomuksesta. Tämän jälkeen osapuolet toteavat ja vahvistavat kriisin olemassaolon, reagoivat eri tavoin kriisiin ja lopuksi kriisiä pyritään sovittelemaan tai korjaamaan. Sosiaalinen draama päätyy joko kriisin ratkeamiseen ja sovitteluun tai kriisin jatkumiseen. Morgan (2001) on kuvannut eräässä amerikkalaisessa yhteisössä käytyä kiistaa maankäytöstä sosiaalisen draaman mallin avulla. Alueen asukkaat kiistelivät rakennuttajan kanssa tärkeälle luonnonpaikalle rakennettavista arvoasunnoista. Morgan kuvaa kiistan etenemistä sosiaalisena draamana: paikallisen sanomalehden uuti- 
sointi ja maisemansuojelun puolesta järjestäytyneiden kansalaisten retoriikka osoittivat välirikon. Kriisiä soviteltiin suosituissa yleisötilaisuuksissa, joissa kaupungin suunnittelulautakunta vastasi huolestuneiden kansalaisten kysymyksiin ja huomautuksiin. Kiistan yksi ratkaisu oli se, että yksityishenkilö osti rakennettavaksi aiotun maan ja liitti sen suojelualueeseen. Sosiaalisessa draamassa olivat vastakkain käsitykset yksilöstä oikeuksineen ja yksilön moraalisesta ja vastuullisesta yhteisön jäsenyydestä. Tutkimuksessa kuvattu erimielisyys luonnosta johdatti tarkastelemaan kulttuurisia käsityksiä asumisesta ja ihmisenä olemisesta.

4) Kullakin puheyhteisöllä on omaa sanastoa yhteisön viestinnän kuvaamiseen. Carbaughin (1989) esittämä ja jo laajasti testattu teoria viestinnän kulttuurisista termeistä (cultural terms for talk) ohjaa tarkastelemaan viestintäkäyttäytymiselle annettuja yhteisön omia termejä tai termiryppäitä. Termien käyttö ja niille annetut tulkinnat sisältävät yhteisössä yhteisesti jaettuja käsityksiä ihmisyydestä, sosiaalisista suhteista ja itse viestinnästä. Esimerkiksi Baxterin (1993) tutkimuksessa kuvattiin kahta erilaista alakulttuuria eräässä yliopistossa. "Asioiden läpipuhuminen" (talking things through) -ilmaisu johdatti Baxterin kuvaamaan laitosten opetushenkilökunnan kollegiaalisuutta korostavaa toimintatapaa, kun taas yliopiston hallintohenkilökunnan käyttämä ilmaisu "asioiden paperille paneminen" (putting it in writing) ilmensi Baxterin mukaan ammattihallintoa arvostavaa toimintatapaa. (Baxter 1993, $313,316-325$.)

\section{VIESTINNÄN ETNOGRAFIAN KRITIIKKIÄ}

Lähtökohtana voidaan pitää, ettei mikään viestinnän tutkimuksen näkökulma yksin riitä kuvaamaan viestinnän monimuotoisuutta eikä mikään viestinnän tutkimuksen näkökulma myöskään täten säästy kriittiseltä tarkastelulta. Philipsen, Coutu ja Covarrubias (2005) tiivistävät viestinnän etnografiseen tutkimukseen kohdistuvan kritiikin kuvatessaan nimenomaan puhekooditeoriaan kohdis- 
tunutta kritiikkiä ja esittävät, että kritiikissä on kaksi teemaa: 1) viestinnän etnografia (tai erityisesti puhekooditeoria) ei ota huomioon valtaa ja sen esiintymistä viestinnässä ja 2) viestinnän etnografiassa (tai puhekooditeoriassa erityisesti) tarkastellaan kulttuuria liian deterministisesti tai liian staattisena. Molemmat teemat ovat esiintyneet erityisesti kriittisen kulttuurintutkimuksen tutkijoiden mutta myös muiden vuorovaikutuksen tutkijoiden esittäminä. Kahdessa viestinnän alan tunnetussa lehdessä, Quarterly Journal of Speech ja Research on Language and Social Interaction, keskusteltiin 1990-luvun alussa viestinnän etnografisen tutkimuksen ja kriittisen tutkimuksen eroista. Esimerkiksi Carbaugh (1989/1990) pohti, miten ja mitä kohtaan tutkija esittää tutkimuksessaan kritiikkiä. Fitchin (1994) ja Lannamannin (1994) vuoropuhelu Communication Yearbook:issa tiivistää aiemmat keskustelut. Keskustelu jatkuu edelleen: National Communication Associationin vuoden 2007 konferenssissa palataan taas kerran viestinnän etnografisen tutkimuksen näennäiseen kritiikittömyyteen ${ }^{1}$.

Keskustelu vallan olemuksesta ja tutkimuksesta on (myös) keskustelua tutkijan roolista ja siitä, mitä tutkija voi tietää. Kun viestinnän etnografista tutkimusta kuvataan vallan olemassaolon unohtavaksi tai väheksyväksi tai kun viestinnän etnografinen tutkimus määritellään epäpoliittiseksi tai kriittisyyttä vältteleväksi, viestinnän etnografisen tutkimuksen näkökulmasta voidaan kysyä, tulisiko valtaa tai epätasa-arvoa tutkia tutkijan vai tutkittavien näkemyksenä (Fitch 1994, 108). Fitch esittää, että koska viestinnän etnografisen tutkimuksen keskeisin sitoumus on tarkastella viestintää natiivien tai paikallisten tulkinnoissa ja toiminnassa, eivät ensisijaisia ole silloin tutkijan havainnot esimerkiksi alistamisesta vaan tutkittavien kuvauksista ja tulkinnoista alistavista viestintäteoista yhteisössään. Lisäksi Fitch $(1994,107)$ pohtii, että jos huomio on tutkimuksessa lähtökohtaisesti aina epätasa-arvoisissa suhteissa, vähemmälle huomiolle jäävät ihmisten kokemukset tasa-arvoisista ja harmonisista suhteista, jotka ovat yhtä mielenkiintoisia tai mer-

\footnotetext{
${ }^{1}$ Language and Social Interaction -ryhmän yksi paneeleista on otsikoitu "Critique in ethnography of communication: renewing the dialogue".
} 
kittäviä tutkimuksen kohteita. Valta on vain yksi vuorovaikutuksessa ilmenevistä sosiaalisen toiminnan piirteistä, eikä tutkimuksessa ole aiheellista nostaa keskiöön yhtä piirrettä perusteitta.

Carbaugh (1989/1990) on pohtinut, mitä kriittisyys tarkoittaa viestinnän etnografisessa tutkimuksessa. Hän esittää, että - kuten kaikessa tutkimuksessa - myös viestinnän etnografiassa tutkimusta ja teoreettisia konstruktioita voidaan tarkastella kriittisesti. Esimerkiksi Scollo ja Poutiainen (2006) ovat tarkastelleet viestinnän etnografisissa tutkimuksissa kuvattuja suomalaisten, läntisten apassien ja kolumbialaisten kulttuurisia käsityksiä romanttisesta parisuhteesta ja viestinnästä suhteen aloittamisessa. Scollon ja Poutiaisen mukaan viestinnän etnografinen tutkimus osoittaa huomattavan variaation käsityksissä ja he esittävätkin, että interpersonaalisen viestinnän kirjallisuudesta tuttu romanttisen parisuhteen etenemismalli (Knapp \& Vangelisti 2005) on kulttuurisidonnainen ja siksi selitysvoimaltaan varsin rajallinen.

Carbaugh (1989/1990) esittää myös, että tieteen tekemiseen kohdistuvan kriittisyyden lisäksi tutkija voi valita yksityiskohtaisen ja järjestelmällisen kuvauksensa kohteeksi tutkittaviensa ilmaisemia, heille itselleen merkittäviä kriittisiä käsityksiä esimerkiksi viestintäyhteisön arvoista, toimintatavoista tai toteutumattomasta tasa-arvosta. Viestinnän etnografisessa tutkimuksessa on useita esimerkkejä Carbaughn kuvaamista eri kriittisyyden muodoista. Esimerkkinä tästä on Basson (1979) tutkimus, jossa analysoitiin sellaisia kenttämuistiinpanoihin ja ääninauhalle tallennettuja vuorovaikutustilanteita, joissa läntiset apassit imitoivat keskenään humoristisesti "valkoisen miehen" puhetta ja nonverbaalista viestintää. Imitoiminen merkitsi Basson mukaan läntisille apasseille mahdollisuutta "valkoisen miehen" valtakulttuurin vastustukseen ja oman kulttuurin erityisyyden yhteiseen tunnistamiseen. Basso osoittaa tutkimuksellaan "valkoisen miehen" alistavan ja ymmärtämättömän suhtautumisen intiaanien elämää ja erityisesti viestintää kohtaan. 
Viestinnän etnografiseen tutkimukseen kohdistuvan kritiikin toinen teema liittyy kulttuurin käsitteellistämiseen ja (viestintä)kulttuurien kuvaukseen tutkimuksen tuloksena. Viestinnän etnografisen tutkimuksen yksi lähtökohta on tarkastella viestintää järjestäytyneenä systeeminä. Vaikka viestintä nähdään sellaisena, josta on havaittavissa malleja, toistuvia muotoja ja säännönmukaisuuksia, ei esimerkiksi rituaalien tai muiden toistuvien viestinnän muotojen kuvaus tarkoita sitä, että viestintä olisi täysin ennustettavaa tai ennakoitavaa toimintaa. Myös viestinnän etnografisessa tutkimuksessa ihmisen toimintaa tarkastellaan sellaisena, jossa on vastustuksen tai muutoksen elementtejä, eikä siis suinkaan staattisena. Väite, että viestinnän etnografiset tutkimukset esittävät viestintäkulttuureista yksipuolisen, pysähtyneen ja deterministisen kuvan, on ristiriidassa viestinnän etnografian lähtökohtien ja tavoitteiden kanssa.

Viestinnän etnografisessa tutkimuksessa kulttuuri ei tarkoita maantieteellisesti rajattua aluetta tai kansallisuutta. Tällainen määritelmä liittyy kulttuurienvälisen viestinnän traditionaaliseen näkökulmaan. Viestinnän etnografiassa sen sijaan kulttuuri voidaan määritellä esimerkiksi viestintätekoina, kulttuurisena diskurssina tai yhteisön jakamina asenteina ja arvoina. Carbaugh (1988a) on esittänyt, että viestintä on kulttuurista, kun siihen liittyy syviä tunteita (deeply felt), kun yhteisön jäsenet yhteisesti ja jollakin tavalla yhtäläisesti tunnistavat ja ymmärtävät sitä (commonly intelligeble) ja kun yhteisön jäsenet (tai ainakin osa heistä) voivat osallistua tällaiseen viestintään tai tilanteeseen (widely accessible).

\section{SUOMALAINEN PUHEKULTTUURI VIESTINNÄN ETNOGRAFIAN NÄKÖKULMASTA}

Suomalaista kulttuurista viestintää on viimeisen kymmenen vuoden aikana tutkittu paljon viestinnän etnografisesta näkökulmasta. Tutkimuksissa on tarkasteltu viestintää erilaisissa konteksteissa, kuten julkisissa tai yleisötilanteissa (Wilkins 2005), opetustilan- 
teissa (Carbaugh 1995a; Wilkins 1999), työpaikalla (Carbaugh \& Poutiainen 2000) tai vierailujen aikana (Poutiainen 2004). Tutkimuksissa on analysoitu medioidun viestinnän kulttuurisia tulkintoja (Berry 1995; Carbaugh \& Berry 2001), suomalaisen formaalin keskustelun sääntöjä (Carbaugh 1995a), naisten puhetta seurustelusta (Poutiainen 2005), suomalaista käsitystä luonnosta (Carbaugh 1996), hiljaisuudesta (Carbaugh, Berry \& Nurmikari-Berry 2006) ja matkapuhelinviestinnästä (Poutiainen 2007). Vertailevia tutkimuksia on tehty suomalaisten ja amerikkalaisten tulkinnoista eri vuorovaikutustilanteissa, kuten virallisissa esittely- tai tutustumistilanteissa työpaikalla (Carbaugh \& Poutiainen 2000), suomalaisten ja amerikkalaisten naisten erilaisista käsityksistä romanttisen parisuhteen aloittamisesta (Poutiainen 2005) ja suomalaisten ja amerikkalaisten tulkinnoista ihmisenä olemisesta ja kulttuurisista myyteistä Kramer vs. Kramer -elokuvassa (Berry 1995).

Suomalaista kulttuurista viestintää tai puhekulttuurille merkittäviä viestintätilanteita tai -paikkoja on toki tutkittu ansiokkaasti myös muista näkökulmista. Esimerkiksi antropologi Roberts (1982) kuvaa hämäläisen kylän elämää, suhteita ja samalla sen vuorovaikutusta. Erityisesti Robertsin kuvaukset juhlista ja kahvittelusta ovat kulttuurisen viestinnän tutkijalle mielenkiintoisia. Yhteistä Robertsin ja viestinnän etnografisille tutkimuksille on, että niissä on tarkasteltu viestintää syvällisesti kulttuurisena, ei viestinnän kontekstina tai muuttujana, ja että niissä tutkimuksen keskeisimpänä tavoitteena on ollut paikallisten maailmankuvan ja toiminnan ymmärtäminen itse toimijoiden näkökulmasta.

Nostan seuraavassa tarkasteluun kaksi tutkimusta, jotka valaisevat suomalaista puhekulttuuria hieman eri näkökulmista. Toisessa tutkimuksessa tutkija kiinnitti kenttätyötä tehdessään huomionsa paikallisten eli suomalaisten tuottamaan ja aktiivisesti arkipuheessa kommentoimaan viestinnän muotoon. Toisessa tutkimuksessa tutkija on kuvannut universaalin viestinnän ilmiötä, hiljaisuutta ja sen kulttuurisia tulkintoja. 
Havainnoidessaan opetusviestintää Tampereen seudulla yliopistossa ja kansanopistoissa Wilkins (1999) kiinnitti huomionsa viestintään, jota hän väitöskirjassaan kuvaa asia puheeksi. Asiallista viestintätyyliä odotettiin Wilkinsin mukaan kaikilta opetustilanteeseen osallistujilta: opettajalta, opiskelijoilta, puhujilta ja kuuntelijoilta. Wilkins (2005) laajensi myöhemmin analyysinsä koskemaan yleensä yleisö- ja julkisia tilanteita ja kuvasi asiallista tyyliä nonverbaalisen viestinnän optimaalina muotona. Asialliseen nonverbaaliseen viestintään liittyy muun muassa kasvojen ilmeettömyys ja nonverbaalisten eleiden vähäisyys. Wilkins (2005) määrittelee asiasta puhumisen tai asiallisen tyylin suoraksi, faktoihin keskittyväksi, päämäärätavoitteiseksi, kontrolloiduksi ja tunneilmauksia välttäväksi puhetyyliksi tai -tavaksi, jonka vastakohtana on henkilökohtaisista tai yksityisistä asioista, tunteista ja tabuista puhuminen tai huomion kiinnittäminen vaikkapa tilanteen ilmapiiriin. Asiallinen tyyli tulkitaan rehelliseksi ja aidoksi. Wilkins (1999) päätyy ehdottamaan, että puhekulttuurit voidaan jakaa suhdekeskeisiin, viestintäkeskeisiin ja informaatiokeskeisiin kulttuureihin, suomalaisen puhekulttuurin kuuluessa viimeiseen ryhmään.

Hiljaisuus on tähän mennessä kiinnittänyt eniten huomiota suomalaisen puhekulttuurin piirteenä ja erityispiirteenä (ks. ainakin Carbaugh, Berry \& Nurmikari-Berry 2006; Lehtonen \& Sajavaara 1985; Sajavaara \& Lehtonen 1997). Carbaugh ym. (2006) tutkivat sitä, millaista on suomalaisille "luonnollinen tapa olla" ja esittävät kuvauksensa keräämiensä kenttähavaintojen, haastatteluiden ja videomateriaalin perusteella. He esittävät ensinnäkin, että suomalaiset itse kuvaavat, että on "luonnollista tai normaalia" olla hiljaa. Suomalaista hiljaisuutta kuvaa parhaiten sana quietude, eikä esimerkiksi silence. Lisäksi he esittävät, että hiljaisuuteen Suomessa liitetty ujous ja sen englanninkielinen käännös shyness merkitsevät suomalaiselle ja amerikkalaiselle puhujalle eri asioita: shyness on neutraali, useimmiten kielteinen ominaisuus amerikkalaiselle, kun taas viime aikoihin asti ujous ei suomalaiselle puhujalle ole merkinnyt erityistä kielteistä yksilön ominaisuutta tai piirrettä. Suomalaisissa tulkinnoissa hiljaisuuteen voi liittyä "mietiskely" ja 
"omissa oloissaan oleminen", jotka kaikki ovat "luonnollisia tapoja olla". Carbaugh ym. $(2006,215-216)$ tiivistävät pohdintansa seuraavasti: Suomalaisessa sosiaalisessa elämässä on ajoittain hiljaisuutta. Ihmisillä on perustarve olla hetkittäin hiljaa tai niin, etteivät muut häiritse. Tällaiset hetket ovat luonnollisia ja normaaleja. Hiljaa voidaan olla yksin tai toisten kanssa niin yksityisissä kuin julkisissa tiloissa. Hiljaa olemisen hetket liittyvät yksilön yksityisyyteen, jota muiden tulisi kunnioittaa. Hiljaa oleminen liittyy myös rauhalliseen olemiseen ja se mahdollistaa yksilön kehittymisen ja kasvamisen. Puhuminen on potentiaali uhka hiljaa olemisen hetkille.

Aiemmissa viestinnän etnografisissa tutkimuksissa (ks. esim. Basso 1990a; Braithwaite 1990) on tarkasteltu erityisesti intiaanien käsityksiä hiljaisuudesta ja heidän tapojaan olla hiljaa. Intiaanien tapoja ja käsityksiä on kuvattu "valkoisista" poikkeavana, ja johtopäätöksissä onkin todettu, että puhuminen ja puhumattomuus sekä hiljaisuus, hiljaisuuden ja hiljaisuudella viestiminen ovat kulttuurisia käsityksiä. Vaikka hiljaisuus lieneekin universaali ilmiö, käsitykset sen olemuksesta, merkityksestä, sopivasta määrästä tai sen puuttumisesta ovat kulttuurisia määritelmiä ja kulttuurisesti tuotettuja.

\section{PÄÄTÄNTÖ}

Viestinnän etnografisella näkökulmalla on paikkansa (puhe)viestinnän tutkimuksessa. Perustelen näkemystäni kahdella toisiinsa liittyvällä havainnolla. Ensinnäkin viestinnän etnografinen tutkimus on osoittanut useita kulttuurisia konstruktioita viestinnän teoreettisten mallien taustalla, ja toiseksi viestinnän etnografinen tutkimus on laajentanut käsitystämme viestinnän moni-ilmeisyydestä ja monenlaisista merkityksistä.

Pääosa viestinnän tutkimuksesta tehdään Yhdysvalloissa. On ymmärrettävää, että viestinnän teoreettiset mallit, silloin kun niitä ei voida tarkastella universaaleina, heijastavat syntysijojansa ja 
luojiensa kulttuurisia käsityksiä maailmasta. Viestinnän etnografiset tutkimukset ovat jo osoittaneet, että useat keskeiset, erityisesti interpersonaalisen viestinnän tutkimuksessa sovelletut konstruktiot eivät ole universaaleja ilmiöitä. Viestinnän tutkimuksen peruskäsitteet kuten communication (Katriel \& Philipsen 1990), the self ja relationship (Carbaugh 1989) resonoivat amerikkalaisen ihmisja suhdekäsityksen kanssa ja liittyvät keskeisesti amerikkalaiseen interpersonaaliseen ideologiaan (Fitch 1998). Viestinnän etnografisella tutkimuksella on keskeinen rooli näiden kulttuuristen konstruktioiden tunnistamisessa, kuvaamisessa ja täten viestinnän teorian kehittämisessä.

Edelliseen läheisesti liittyen viestinnän etnografinen tutkimus on esittänyt kuvauksia hyvin erilaisista puheyhteisöistä, erilaisista tavoista arvostaa tai käsittää viestintä, erilaisista tavoista olla vuorovaikutuksessa toisten ihmisten kanssa ja tavoista ymmärtää ihmisenä olemista. Jokaista puheyhteisöä on pyritty kuvaamaan siten kuin yhteisön jäsenet itsensä ja toimintansa näkevät. Viestinnän etnografia viestinnän ja kulttuurin välistä suhdetta tulkitsevana teoriana pyrkii kuvaamaan viestinnän kulttuurisuuden ja puheyhteisöjen moninaisuutta.

\section{KIRJALLISUUS}

Basso, K. 1979. Portraits of "the Whiteman". Linguistic play and cultural symbols among the Western Apache. Cambridge, MA: Cambridge University Press.

Basso, K. 1990a. "To give up on words": silence in Western Apache culture. Teoksessa D. Carbaugh (toim.) Cultural communication and intercultural contact. Hillsdale, NJ: Lawrence Erlbaum, 303-320.

Basso, K. 1990b. Western Apache language and culture. Essays in linguistic anthropology. Tucson, AZ: University of Arizona Press.

Baxter, L. A. 1993. "Talking things through" and "putting it in writing": two codes of communication in an academic institution. Journal of Applied Communication Research 21 (4), 313-326.

Berry, M. 1995. If you run away from a bear you will run into a wolf: Finnish responses to Joanna Kramer's identity crisis. Teoksessa J. Knuf (toim.) Texts and identities. Proceedings of the third Kentucky conference on narratives 1994. Lexington: University of Kentucky, 32-48. 
Bloch, L.-R. 2003. Who's afraid of being a freier? The analysis of communication through a key cultural frame. Communication Theory 13 (2), 125-159.

Braithwaite, C. 1990. Communicative silence: a cross-cultural study of Basso's hypothesis. Teoksessa D. Carbaugh (toim.) Cultural communication and intercultural contact. Hillsdale, NJ: Lawrence Erlbaum, 321-327.

Carbaugh, D. 1988a. Comments on "culture" in communication inquiry. Communication Reports 1 (1), 38-41.

Carbaugh, D. 1988b. Talking American: cultural discourses on Donahue. Norwood, NJ: Ablex.

Carbaugh, D. 1989. Fifty terms for talk: a cross-cultural study. International and Intercultural Communication Annual 13, 93-120.

Carbaugh, D. 1989/1990. The critical voice in ethnography of communication research. Research on Language and Social Interaction 23, 261-282.

Carbaugh, D. 1995a. "Are Americans really superficial?" Notes on Finnish and American cultures in linguistic action. Teoksessa L. Salo-Lee (toim.) Kieli \& kulttuuri oppimisessa ja opettamisessa / Language \& culture in teaching and learning. Jyväskylän yliopisto. Viestintätieteiden laitoksen julkaisuja 12, 53-60.

Carbaugh, D. 1995b. The ethnographic communication theory of Philipsen and associates. Teoksessa D. P. Cushman \& B. Kovacic (toim.) Watershed research traditions in human communication theory. Albany, NY: SUNY Press, 269-297.

Carbaugh, D. 1996. Naturalizing communication and culture. Teoksessa J. Cantrill \& C. Oravec (toim.) The symbolic earth: discourse and our creation of the environment. Lexington: University of Kentucky Press, 38-57.

Carbaugh, D. 1998. "I can't do that" but "I can actually see around corners": American Indian students and the study of public communication. Teoksessa J. N. Martin, T. K. Nakayama \& L. A. Flores (toim.) Readings in cultural context. Mountain View, CA: Mayfield, 160-172.

Carbaugh, D. 1999. "Just listen": listening and landscape among the Blackfeet. Western Journal of Communication 63 (3), 250-270.

Carbaugh, D. 2001. "The people will come to you": Blackfeet narrative as a resource for contemporary living. Teoksessa J. Brockmeier \& D. Carbaugh (toim.) Narrative and identity. Amsterdam: J. J. Benjamins, 103-127.

Carbaugh, D. \& Berry, M. 2001. Communicating history, Finnish and American discourses: an ethnographic contribution to intercultural communication inquiry. Communication Theory 11 (3), 352-366.

Carbaugh, D., Berry, M. \& Nurmikari-Berry, M. 2006. Coding personhood through cultural terms and practices: silence and quietude as a Finnish "natural way of being". Journal of Language and Social Psychology 25 (3), 203-220. 
Carbaugh, D., Gibson, T. \& Milburn, T. 1997. A view of communication and culture: scenes in an ethnic cultural center and a private college. Teoksessa B. Kovacic (toim.) Emerging theories of human communication. Albany, NY: SUNY Press, 1-24.

Carbaugh, D. \& Poutiainen, S. 2000. By way of introduction: an American and Finnish dialogue. Teoksessa M. Lustig \& J. Koester (toim.) AmongUS: essays in identity, belonging, and intercultural competence. New York: Addison \& Wesley Longman, 203-212.

Carbaugh, D. \& Rudnick, L. 2006. Which place, what story? Cultural discourses at the border of the Blackfeet reservation and Glacier national park. Great Plains Quarterly 26 (3), 167-184.

Carey, J. 1989. Communication as culture: essays on media and society. Winchester, MA: Unwin Hyman.

Coutu, L. 2000. Communication codes of rationality and spirituality in the discourse of and about Robert S. McNamara's In Retrospect. Research on Language and Social Interaction 33 (2), 179-211.

Craig, R. T. 1999. Communication theory as a field. Communication Theory 9 (2), 119-161.

Fitch, K. L. 1991. The interplay of linguistic universals and cultural knowledge in personal address: Colombian madre terms. Communication Monographs $58(3), 254-272$.

Fitch, K. L. 1994. Culture, ideology, and interpersonal communication research. Teoksessa S. A. Deetz (toim.) Communication Yearbook 17. Beverly Hills: Sage, 104-135.

Fitch, K. L.1997. A ritual for attempting leave-taking in Colombia. Teoksessa J. N. Martin, T. K. Nakayama \& L. A. Flores (toim.) Readings in cultural context. Boston, MA: McGraw-Hill College, 179-186.

Fitch, K. L. 1998. Speaking relationally. Culture, communication and interpersonal connection. New York: Guilford Press.

Geertz, C. 1973. The interpretation of cultures. Selected essays. New York: Basic Books.

Hakulinen, A.1989. Keskustelun luonnehtimisesta konteksti- ja funktionaalisten tekijöiden nojalla. Suomalaisen keskustelun keinoja I. Kieli 4. Helsinki: Helsingin yliopiston suomen kielen laitos, 41-72.

Hall, B. J. 1997. Ritual as part of everyday life. Teoksessa J. N. Martin, T. K. Nakayama \& L. A. Flores (toim.) Readings in cultural context. Boston, MA: McGraw-Hill College, 172-179.

Hall, B. J. \& Valde, K. 1995. "Brown-nosing" as a cultural resource in American organizational speech. Research on Language and Social Interaction 28 (4), $131-150$.

Hiemstra, G. 1983. You say you want a revolution? "Information technology" in organizations. Teoksessa R. N. Bostrom (toim.) Communication Yearbook 7. Beverly Hills: Sage, $802-827$. 
Ho, E. 2006. Behold the power of Qi: the importance of Qi in the discourse of acupuncture. Research on Language and Social Interaction 30 (4), 411-440.

Huspek, M. \& Kendall, K. E. 1991. On withholding political voice: and analysis of the political vocabulary of a "nonpolitical" speech community. The Quarterly Journal of Speech 77 (1), 1-19.

Hymes, D. 1962. The ethnography of speaking. Teoksessa T. Gladwin \& W. Sturtevant (toim.) Anthropology and human behavior. Washington, DC: Anthropological Society of Washington, 13-53.

Hymes, D. 1972. Models of the interaction of language and social life. Teoksessa J. J. Gumperz \& D. Hymes (toim.) Directions in sociolinguistics: the ethnography of communication. New York: Holt, Rinehart \& Winston, 35-71.

Katriel, T. 1986. Talking straight: 'Dugri' speech in Israeli Sabra culture. Cambridge: Cambridge University Press.

Katriel, T. 2004. Dialogic moments. From soul talks to talk radio in Israeli culture. Detroit, MI: Wayne State University Press.

Katriel, T. \& Philipsen, G. 1990. "What we need is communication": "Communication" as a cultural category in some American speech. Teoksessa D. Carbaugh (toim.) Cultural communication and intercultural contact. Hillsdale, NJ: Lawrence Erlbaum, 77-93.

Knapp, M. L. \& Vangelisti, A. L. 2005. Interpersonal communication and human relationships. Boston: Allyn and Bacon.

Lannamann, J. 1994. The problem with disempowering ideology. Teoksessa S. A. Deetz (toim.) Communication Yearbook 17. Beverly Hills: Sage, 136-147.

Leeds-Hurwitz, W. (toim.) 1995. Social approaches to communication. New York: Guilford Press.

Leeds-Hurwitz, W. 2005. Ethnography. Teoksessa K. L. Fitch \& R. E. Sanders (toim.) Handbook of language and social interaction. Mahwah, NJ: Lawrence Erlbaum, 327-353.

Lehtonen, J. \& Sajavaara, K. 1985. A silent Finn. Teoksessa D. Tannen \& M. Saville-Troike (toim.) Perspectives on silence. Norwood, NJ: Ablex, 193-201.

Milburn, T. 2004. Speech community: reflections upon communication. Teoksessa P. J. Kalbfleisch (toim.) Communication Yearbook 28. Mahwah, NJ: Lawrence Erlbaum, 411-441.

Morgan, E. 2001. Communicating environment: cultural discourses of place in the Pioneer Valley of Western Massachusetts. Department of Communication, University of Massachusetts Amherst. Unpublished doctoral dissertation.

Philipsen, G. 1975. Speaking like a man in Teamsterville: culture patterns of role enactment in an urban neighborhood. Quarterly Journal of Speech 62 (1), $15-25$. 
Philipsen, G. 1990. An ethnographic approach to communication studies. Teoksessa B. Dervin, L. Grossberg, B. O'Keefe \& E. Wartella (toim.)

Rethinking communication. Vol. 2: Paradigm exemplars. Newbury Park, CA: Sage, 258-268.

Philipsen, G. 1992. Speaking culturally. Albany, NY: SUNY Press.

Philipsen, G. 2002. Cultural communication. Teoksessa W.B. Gudykunst \& B. Mody (toim.) Handbook of international and intercultural communication. 2.painos. Thousand Oaks: Sage, 51-67.

Philipsen, G. \& Carbaugh, D. 1986. A bibliography of fieldwork in the ethnography of communication. Language in Society 15 (3), 387-398.

Philipsen, G., Coutu, L. \& Covarrubias, P. 2005. Speech codes theory: restatement, revisions, and response to criticisms. Teoksessa W. Gudykunts (toim.) Theorizing about intercultural communication. Thousand Oaks, CA: Sage, 55-68.

Poutiainen, S. 2004. Vieras on hyvä ja ottaa. Vuorovaikutusta kahvipöydässä. Teoksessa M. Knuuttila, J. Pöysä \& T. Saarinen (toim.) Suulla ja kielellä. Tulkintoja ruuasta. Helsinki: Suomalaisen Kirjallisuuden Seura, 176-191.

Poutiainen, S. 2005. Kulttuurista puhetta deittaamisesta. Puhe ja kieli 25 (3), 123-136.

Poutiainen, S. 2007. Finnish cultural discourses about the mobile phone communication. Department of Communication, University of Massachusetts Amherst. Unpublished doctoral dissertation.

Ray, G. B. 1987. An ethnography of nonverbal communication in an Appalachian communication. Research on Language and Social Interaction 21, 171-188.

Roberst, F. M. 1982. Under the North Star: notions of self and community in a Finnish village. Department of Anthropology, City University of New York. Unpublished doctoral dissertation.

Sajavaara, K. \& Lehtonen, J. 1997. The silent Finn revisited. Teoksessa A. Jaworski (toim.) Silence. Interdisciplinary perspectives. Berlin: Mouton de Gruyter, 263-283.

Sawyer, M. S. 2005. Nonverbal ways of communicating with nature: a crosscase study. Environmental Communication Yearbook 1, 227-249.

Schneider, D. 1976. Notes toward a theory of culture. Teoksessa K. Basso \& H. Selby (toim.) Meanings in anthropology. Albuquerque, NM: University of New Mexico Press, 197-220.

Scollo, M. \& Poutiainen, S. 2006. A cultural critique of relationship stage models. Paper presented in World Communication Association Annual Conference, Springfield, MA, USA.

Sequiera, D. 1993. Personal address as negotiated meaning in an American church community. Research on Language and Social Interaction 26 (3), 259-285. 
Suopis, C. \& Carbaugh, D. 2005. Speaking about menopause: possibilities for a cultural discourse analysis. Teoksessa J. F Duchan \& D. Kovarsky (toim.) Diagnosis as cultural practice. Berlin: Mouton de Gruyter, 263-276.

Suter, E. A. 2000. Focus groups in ethnography of communication: expanding topics of inquiry beyond participant observation. The Qualitative Report $5(1-2), 1-2 .<$ http://www.nova.edu/ssss/QR/QR5-1/suter.html>. Viitattu 17.1.2007.

Townsend, R. 2004. Deliberation and democracy: ethnography of rhetoric in a New England town meeting. Department of Communication, University of Massachusetts Amherst. Unpublished doctoral dissertation.

Turner, V. 1980. Social dramas and stories about them. Critical Inquiry 7 (1), $141-168$.

Wilkins, R. 1999. 'Asia' (matter-of-fact) communication: Finnish cultural terms for talk in education scenes. Department of Communication, University of Massachusetts at Amherst. Unpublished doctoral dissertation.

Wilkins, R. 2005. The optimal form: inadequacies and excessiveness within the asiallinen [matter of fact] nonverbal style in public and civic settings in Finland. Journal of Communication 55 (2), 383-401.

Winchatz, M. 2001. Social meanings in German interactions: an Ethnographic analysis of the second-person pronoun sie. Research on Language and Social Interaction 34 (3), 337-369. 